\title{
HEDONIC PRICE FOR AMENITIES IN RURAL AND URBAN RESIDENTIAL CONDOMINIUMS IN COSTA RICA
}

\author{
Javier Paniagua-Molina \\ University of Costa Rica \\ e-mail: Javier.paniagua@ucr.ac.cr \\ Johanna Solórzano-Thompson \\ University of Costa Rica \\ e-mail: johanna.solorzano@ucr.ac.cr
}

\section{Carlos González-Blanco}

Bch. Agricultural Economics and Agribusiness, University of Costa Rica

e-mail:cgonzalez1795@gmail.com

\section{David Barboza-Navarro}

Bch. Agricultural Economics and Agribusiness, University of Costa Rica e-mail:josdavbn@gmail.com

\begin{abstract}
As the number of homes located in condominiums increases, investigations should be promoted to determine the implied price of additional amenities over the total price of the property. This study evaluated the impact of multi-attribute and construction variables on the value of condominiums in Costa Rica, using a hedonic pricing model of the amenities that influence the total price. Information from condominiums located in all provinces of the country was used to determine the importance of the variables studied. Through multiple regression analysis, it was determined that nine amenities explain the behavior of the total price. This study shows that the project's internal and external variables have a significant effect on sales prices and consumers' purchasing decisions. The most significant variables were income, construction area, access to a pool and gym, and the type of condominium.
\end{abstract}

Key words: externalities, valuation models, real estate valuation, property market, amenities.

JEL Classification: C51, R31.

Citation: Paniagua-Molina, J., Solórzano-Thompson, J., González-Blanco, C., \& Barboza-Navarro, D. (2021). Hedonic price for amenities in rural and urban residential condominiums in Costa Rica. Real Estate Management and Valuation, 29(3), 52-64.

DOI: https://doi.org/10.2478/remav-2021-0021

\section{Introduction}

For several years, Costa Rica has migrated to a type of housing development that optimizes the amount of services for clients and users in one place. Access to housing is a human right and has been perceived as a basic need, and thus dwellings are considered crucial investment assets (Tetteh, 2019).

The construction companies of real estate projects initially offered horizontal condominiums, but, in recent years, the market trend demands more compact vertical properties located in urban centers, with amenities in common spaces, security and controlled access (Cubero, 2018). The construction of 
apartments and condominiums had a relative share of $20 \%$ with respect to total residential construction in 2017, with a reduction of 5\% the following year (Solano \& Aguilar, 2019). In 2017, more than $6 \%$ of inhabited housing was located in private residences and condominiums (vertical and horizontal), with an annual increase of $20 \%$ in 2018; however, in 2019, there was a reduction of 5\%, while $25 \%$ of the procedures for housing construction were for vertical buildings (INEC, 2020; Madrigal, 2020).

Despite the recent instability of the Costa Rican real estate market, vertical buildings are an affordable option for new generations (Garza, 2019). In addition, in cities with large urban agglomerations, the population chooses to live in condominium units (Tajima, 2019). This research proposes a hedonic pricing model of the amenities that affect the price of rural and urban residential condominiums in Costa Rica, and is considered a key tool for planning and evaluating the real estate market.

\section{Literature review}

Price models are useful for determining the intrinsic value of the attributes of a property and forecasting the market price of a transaction. These models are complemented by financial valuation models using discounted cash flows without considering market externalities. In this sense, the buildings can be compared with a package of goods and each of their characteristics adds value to the selling price (Monson, 2009).

The first hedonic pricing model was developed to investigate the effect of surface area and distance from the city center on the price of agricultural land (Colwell \& Dilmore, 1999; Haas, 1922). It is now recognized as a valuable tool for the appraisal and valuation of residential properties (Mayer et al., 2019). The hedonic pricing method is also applied to define the price of consumer goods, such as cars, according to the characteristics and condition of the object, as well as consumer preferences (Court, 1939; Cowling \& Cubbin, 1972; Lancaster, 1966).

Hedonic prices are defined as the implicit prices of the characteristics of a good and are presented to the market as historical prices (Rosen, 1974). On the other hand, a market equilibrium model of a good, where supply equals demand, must consider the attributes and characteristics useful to the consumer, and the hedonic pricing model is equivalent for the buyer and seller (Rosen, 1974). The economic component of the relationship between prices and observed characteristics is evident once the price differences between the goods are recognized when comparing the alternative options.

In the real estate market, many authors have used the hedonic pricing approach with reliable valuation models for houses, condos and apartments (Chan et al., 1998; Frew \& Jud, 2003; Mok et al., 1995; Monson, 2009; Palmquist, 1984; Ridker \& Henning, 1967; Tse, 2002). One of the first academic studies of hedonic pricing theory to analyze the housing market was published by Ridker \& Henning (1967), who evaluated the effect of the improvement of environmental quality on property prices. This method has also been used in specific cases, such as determining the price of large houses based on their amenities (Palmquist, 1984) and the valuation of agricultural land with wildlife habitats that exceeded the prices of land with predominantly agricultural landscapes (Bastian et al., 2002).

A study of the impact of externalities on the sales prices of condos in California showed that, without prohibitive pricing, externalities and the disposition of other variables must be taken into account in estimating property value (Chan et al., 1998). Such is the case of Das et al. (2018), who demonstrated that real estate located in suburban neighborhoods created positive externalities in the price of premium segment assets.

The characteristics of a house can be divided into three types for purposes of valuation, namely: characteristics of the structure, the environment (neighborhood) and location (Chin \& Chau, 2003). Among the variables used to help explain the sale price of a house, the following stand out: square meters $\left(\mathrm{m}^{2}\right)$ of living area and indoor construction, number of rooms and bathrooms, age of the property, size of the lot, number and area of parking spaces, and the location and availability of a swimming pool (Chan et al., 1998; Monson, 2009).

Real estate valuation is often more difficult than other assets because they are not homogeneous, and traditional hedonic pricing models may be susceptible to bias by ignoring attribute externalities (Chan et al., 1998; Das et al., 2018). For this reason, the quantity and quality of the data collected is fundamental in determining the valuation model and establishing significant differences between real estate properties. 


\section{Data and Methods}

Data from the Costa Rican condominium market supply from March to June 2018 were used. It included 537 references of real estate projects in all provinces of the country, coastal, urban and rural areas. However, the largest amount of data corresponded to the central region of Costa Rica, since it has the largest development of condominium housing. Data were collected from the official websites of real estate companies, as well as websites specializing in real estate sales and purchases, with field verification.

A descriptive statistical analysis of the variables used and correlation analysis were carried out to identify their strength of association. If the correlation is high between two independent variables, both variables could measure the same effect on the dependent variable and generate multicollinearity in the econometric model. In this situation, it is decided to eliminate a certain variable and keep the variable that clearly affects the dependent variable.

The dependent variable was defined as the total price of the condominium in dollars (USD), which includes the area and construction as a single asset with multiple attributes. Initially, seventeen independent variables (Table 1) were used to measure the implied price of amenities and property characteristics, selected from literature review and expert consultation.

Heterogeneous goods, such as housing, have a number of built-in characteristics and are sold as an inherent set of characteristics. These characteristics that make up the good are the variables of consumer utility.

Table 1

Independent variables description

\begin{tabular}{cccl}
\hline Variable & Code & Type & \multicolumn{1}{c}{ Details } \\
\hline LOTSIZE & LS & Quantitative & Square meters $\left(\mathrm{m}^{2}\right)$ \\
\hline INCOME & IC & Qualitative & $\begin{array}{l}\text { Social class, where 1=low, 2=medium low, 3=medium, } \\
\text { 4=medium high, 5=high, 6=very high }\end{array}$ \\
\hline FLOORS & FL & Quantitative & $\begin{array}{l}\text { Attribute representing the number of the floor within the } \\
\text { building where the private property is located }\end{array}$ \\
\hline SECURITY & SR & Qualitative & $\begin{array}{l}\text { Security level where 1=basic (access control), 2=medium } \\
\text { (access control and monitoring), 3=full (access, } \\
\text { monitoring, motorized guards) }\end{array}$ \\
\hline SERVICES & SV & Qualitative & Services where 1=basic, 2=medium level, 3=high level \\
\hline SOCIAL & SC & Qualitative & $\begin{array}{l}\text { Social area where 1=none, 2=just a ranch, 3=party room, } \\
\text { 4=club house and beyond }\end{array}$ \\
\hline BATHS & BT & Quantitative & Number of baths for each private property \\
\hline ROOMS & RM & Qualitative & Number of rooms for each private property \\
\hline SPORTS & SP & Qualitative & $\begin{array}{l}\text { Sports infrastructure where 1=none, 2=multipurpose } \\
\text { ground, 3=tennis court, basket area and beyond }\end{array}$ \\
\hline BUILDING & BD & Quantitative & Building area measured in square meters \\
\hline PARKING & PK & Qualitative & Number of parking places \\
\hline SPOOL & PO & Qualitative & Swimming pool where 1=yes, 0=no \\
\hline GYM & GY & Qualitative & Gym where 1=yes, 0=not \\
\hline WTRAILS & WT & Qualitative & Walking trails where 1=yes, 0=no \\
\hline BBQ & BQ & Qualitative & BBQ area where 1=yes, 0=no \\
\hline VERTICAL & VE & Qualitative & Where 1=vertical condominium, 0=horizontal \\
\hline VIEWS & VW & Qualitative & $\begin{array}{l}\text { Views where 1=none, 2=valleys, 3=volcano, 4=lake, } \\
5=\text { gulf, 6=ocean }\end{array}$ \\
\hline
\end{tabular}

Source: own study.

It is difficult to analyze the real estate market with the traditional economic model because it does not consider a single total price. Consequently, a series of hedonic prices must be adopted to express the corresponding characteristics of the property with valuation regression, as each characteristic has its own implicit price (Lancaster, 1966; Miller \& Sklarz, 1987; Rosen, 1974). The total price (PRICE) of the condominium is defined as follows: 
where,

$$
y_{i}=\beta_{0}+\sum_{1}^{k} \alpha_{k} x_{k}+\sum_{1}^{m} \phi_{m} z_{m}+u_{i} \quad \text { with } \quad \begin{aligned}
& (1 \ldots k) \\
& (1 \ldots m)
\end{aligned}
$$

$y_{i}$ represents the total price of $i$-th condo;

$x_{k}$ represents intrinsic variables of $i$-th condo;

$\alpha_{k}$ represents the $k$-th intrinsically attribute of $i$-th condo;

$\phi_{m}$ represents the $m$-th amenity attribute for $i$-th condo.

Ordinary Least Squares (OLS) regression analysis was used and a residue analysis was performed to correct the outlier effects. The outliers were processed through phone calls to confirm the accuracy of the information and, in many cases, were removed to create a second data sample. The first model used all the initial variables proposed with all the available data. Each of the correlations of the coefficients was analyzed to determine statistical significance, i.e. whether or not the coefficients influenced the total price.

Subsequently, a second regression model was run using Weighted Least Squares (WLS), without the outliers, using the two-stage adjusted weights with a "w" weighting factor. In WLS, the observations with higher standard deviation have a relatively lower weight, and the observations with lower standard deviation have a relatively higher weight (Gujarati \& Porter, 2010).

\section{Empirical results}

The descriptive statistical summary of the quantitative variables used in the econometric modeling (Table 2) evidences a high standard deviation for the variables LOTSIZE and BUILDING, seeing as how condominiums of different social classes, location and type were included, with the intention of evaluating the greatest amount of available goods offered in the condominium market.

Table 2

Descriptive statistical summary of the variables used $(n=537)$

\begin{tabular}{crrrrr}
\hline Variable & Mean & Median & Standard Deviation & Min & Max \\
\hline PRICE & $2.27 \mathrm{E}+05$ & $1.80 \mathrm{E}+05$ & $1.94 \mathrm{E}+05$ & $3.40 \mathrm{E}+04$ & $2.00 \mathrm{E}+06$ \\
LOTSIZE & 235.00 & 160.00 & 432.00 & 32.00 & $7.89 \mathrm{E}+03$ \\
BATHS & 2.390 & 2.500 & 0.838 & 1.000 & 6.000 \\
ROOMS & 2.860 & 3.000 & 0.895 & 1.000 & 12.000 \\
BUILDING & 175.000 & 155.000 & 104.000 & 0.000 & $1.00 \mathrm{E}+03$ \\
PARKING & 1.940 & 2.000 & 0.961 & 0.000 & 8.000 \\
\hline
\end{tabular}

Source: own study.

The following is a summary of the frequency analysis for the qualitative variables (Table 3). The sample contains mostly data for medium to medium-high income levels, with private properties located mainly on one and two levels above the ground, with basic levels of security and services.

With respect to sports and recreation-related amenities, about half of the condominiums in the sample had a swimming pool, and most did not have a fitness center for exercise (GY) or trails with green areas for walking (WT). The components of the SOCIAL variable were widely distributed, presenting high diversity, but practically half of the sample had the presence of a BBQ.

About $80 \%$ of the sample consisted of horizontal condominiums with a predominating presence of normal views of the immediate environment or views of valleys, which are common in the Costa Rican real estate market. Condominiums with ocean views were present in the sample, but in a lesser quantity relative to the previous ones.

Correlation analysis (Table 4 and Appendix 1) was carried out to identify the strength of the association between the model variables and to explore association forces and evidence for multicollinearity. Some of the variables presented a medium-high correlation (highlighted in grey). 
Table 3

Frequency summary for qualitative variables used $(n=537)$

\begin{tabular}{|c|c|c|c|c|c|c|c|c|c|}
\hline $\begin{array}{l}\text { Varia- } \\
\text { ble }\end{array}$ & $\begin{array}{l}\text { Cate- } \\
\text { gory }\end{array}$ & $\begin{array}{l}\text { Frequen- } \\
\text { cy }\end{array}$ & $\begin{array}{l}\text { Rela- } \\
\text { tive }\end{array}$ & $\begin{array}{l}\text { Cumu- } \\
\text { late }\end{array}$ & $\begin{array}{c}\text { Varia- } \\
\text { ble }\end{array}$ & $\begin{array}{l}\text { Cate- } \\
\text { gory }\end{array}$ & $\begin{array}{l}\text { Frequen- } \\
\text { cy }\end{array}$ & $\begin{array}{l}\text { Rela- } \\
\text { tive }\end{array}$ & $\begin{array}{c}\text { Cumu- } \\
\text { late }\end{array}$ \\
\hline \multirow{6}{*}{ IC } & 1 & 48 & $8.94 \%$ & $8.94 \%$ & \multirow{3}{*}{ SP } & 1 & 423 & $78.77 \%$ & $78.77 \%$ \\
\hline & 2 & 80 & $14.90 \%$ & $23.84 \%$ & & 2 & 41 & $7.64 \%$ & $86.41 \%$ \\
\hline & 3 & 135 & $25.14 \%$ & $48.98 \%$ & & 3 & 73 & $13.59 \%$ & $100.00 \%$ \\
\hline & 4 & 133 & $24.77 \%$ & $73.74 \%$ & \multirow{2}{*}{ PO } & 0 & 257 & $47.86 \%$ & $47.86 \%$ \\
\hline & 5 & 112 & $20.86 \%$ & $94.60 \%$ & & 1 & 280 & $52.14 \%$ & $100.00 \%$ \\
\hline & 6 & 29 & $5.40 \%$ & $100.00 \%$ & \multirow{2}{*}{ GY } & 0 & 435 & $81.01 \%$ & $81.01 \%$ \\
\hline \multirow{6}{*}{ FL } & 1 & 209 & $38.92 \%$ & $38.92 \%$ & & 1 & 102 & $18.99 \%$ & $100.00 \%$ \\
\hline & 2 & 315 & $58.66 \%$ & $97.58 \%$ & \multirow{2}{*}{ WT } & 0 & 457 & $85.10 \%$ & $85.10 \%$ \\
\hline & 3 & 9 & $1.68 \%$ & $99.26 \%$ & & 1 & 80 & $14.90 \%$ & $100.00 \%$ \\
\hline & 4 & 1 & $0.19 \%$ & $99.44 \%$ & \multirow{2}{*}{ BQ } & 0 & 219 & $40.78 \%$ & $40.78 \%$ \\
\hline & 5 & 1 & $0.19 \%$ & $99.63 \%$ & & 1 & 318 & $59.22 \%$ & $100.00 \%$ \\
\hline & 6 & 2 & $0.37 \%$ & $100.00 \%$ & \multirow{2}{*}{ TP } & 0 & 452 & $84.17 \%$ & $84.17 \%$ \\
\hline \multirow{3}{*}{ SR } & 1 & 443 & $82.50 \%$ & $82.50 \%$ & & 1 & 85 & $15.83 \%$ & $100.00 \%$ \\
\hline & 2 & 91 & $16.95 \%$ & $99.44 \%$ & \multirow{5}{*}{ VW } & 1 & 344 & $64.06 \%$ & $64.06 \%$ \\
\hline & 3 & 3 & $0.56 \%$ & $100.00 \%$ & & 2 & 163 & $30.35 \%$ & $94.41 \%$ \\
\hline \multirow{3}{*}{ SV } & 1 & 368 & $68.53 \%$ & $68.53 \%$ & & 3 & 4 & $0.74 \%$ & $95.16 \%$ \\
\hline & 2 & 132 & $24.58 \%$ & $93.11 \%$ & & 4 & 8 & $1.49 \%$ & $96.65 \%$ \\
\hline & 3 & 37 & $6.89 \%$ & $100.00 \%$ & & 5 & 18 & $3.35 \%$ & $100.00 \%$ \\
\hline \multirow{4}{*}{ SC } & 1 & 192 & $35.75 \%$ & $35.75 \%$ & & & & & \\
\hline & 2 & 177 & $32.96 \%$ & $68.72 \%$ & & & & & \\
\hline & 3 & 109 & $20.30 \%$ & $89.01 \%$ & & & & & \\
\hline & 4 & 59 & $10.99 \%$ & $100.00 \%$ & & & & & \\
\hline
\end{tabular}

Source: own study.

Table 4

V's Cramer coefficient for correlation between independent qualitative variables

\begin{tabular}{|c|c|c|c|c|c|c|c|c|c|c|c|c|}
\hline & IC & FL & SR & SV & SC & SP & PO & GY & WT & BQ & TP & VW \\
\hline IC & 1.000 & & & & & & & & & & & \\
\hline FL & 0.250 & 1.000 & & & & & & & & & & \\
\hline SR & 0.231 & 0.087 & 1.000 & & & & & & & & & \\
\hline SV & 0.225 & 0.187 & 0.212 & 1.000 & & & & & & & & \\
\hline SC & 0.173 & 0.127 & 0.117 & 0.323 & 1.000 & & & & & & & \\
\hline SP & 0.160 & 0.130 & 0.112 & 0.264 & 0.230 & 1.000 & & & & & & \\
\hline PO & 0.163 & 0.099 & 0.137 & 0.185 & 0.463 & 0.219 & 1.000 & & & & & \\
\hline GY & 0.109 & 0.209 & 0.127 & 0.333 & 0.425 & 0.330 & 0.264 & 1.000 & & & & \\
\hline WT & 0.185 & 0.089 & 0.257 & 0.320 & 0.204 & 0.321 & 0.139 & 0.157 & 1.000 & & & \\
\hline $\mathrm{BQ}$ & 0.247 & 0.143 & 0.154 & 0.244 & 0.701 & 0.228 & 0.381 & 0.228 & 0.134 & 1.000 & & \\
\hline $\mathbf{T P}$ & 0.229 & 0.477 & 0.094 & 0.136 & 0.126 & 0.103 & 0.129 & 0.232 & 0.005 & 0.003 & 1.000 & \\
\hline VW & 0.110 & 0.108 & 0.220 & 0.164 & 0.161 & 0.160 & 0.171 & 0.253 & 0.146 & 0.155 & 0.307 & 1.000 \\
\hline
\end{tabular}

Source: own study. 
Cramer's V coefficient is a symmetrical measurement value for the intensity of the relationship between two or more nominal variables, independent of the sample size. This study assumes that, if Cramer's V is greater than 0.30 , a high correlation between qualitative variables is suspected (Table 4). For example, the social areas (SC) variable presents an important correlation with the variables that measure the presence of a BBQ, pool (PO) and gym (GY) in a condominium.

The variables income (IC), building (BD), views (VW), bathrooms (BT) and lot size (LS) have a correlation of more than $50 \%$ with respect to housing prices (Appendix 1 ).

Regarding to independent variables, some of them have a significant bidirectional relation. For example, there is a medium-high correlation between BT and BD with IC, which is related to the social strata that have access to the purchase of more expensive condominiums. In the same way, the number of rooms (RM), bathrooms and parking spaces (PK), as well as LS, are highly related to BD, as the larger the total surface area available, the more of these spaces there are.

The results for OLS models applied to sample one and sample two without outliers (Table 5) show high coefficients of determination $\left(\mathrm{R}^{2}\right)$, i.e., 0.901 and 0.966 respectively. This situation could be the result of multicollinearity, since variables with a medium-high correlation such as BT and RM were not statistically significant, but are correlated with the variable BD, which did present statistical significance. A similar situation occurs with the variables SC and sports infrastructure (SP), which were not significant for the regression of sample one, but showed an important correlation with each other.

The negative sign of the BQ and SC coefficients of the first model (Table 5) could be due to the fact that consumers do not attribute value to these amenities, or the proximity to the home could have a negative effect associated with privacy or noise. In this case, the expected logical values for both coefficients were positive, due to the effect of the increase on the value of the condominium. In the model applied to the second sample (Table 6), these and other variables were eliminated due to the inconsistency in the expected results.

The regression residuals of the OLS model applied to sample one (Fig. 1) have outliers that negatively influence homocedasticity. This situation is verified by the statistical significance of the Breuch-Pagan coefficient (Table 6), which indicates the presence of heteroscedasticity. Figure 2 shows the regression residuals without outliers and with a uniform oscillation around the zero average.

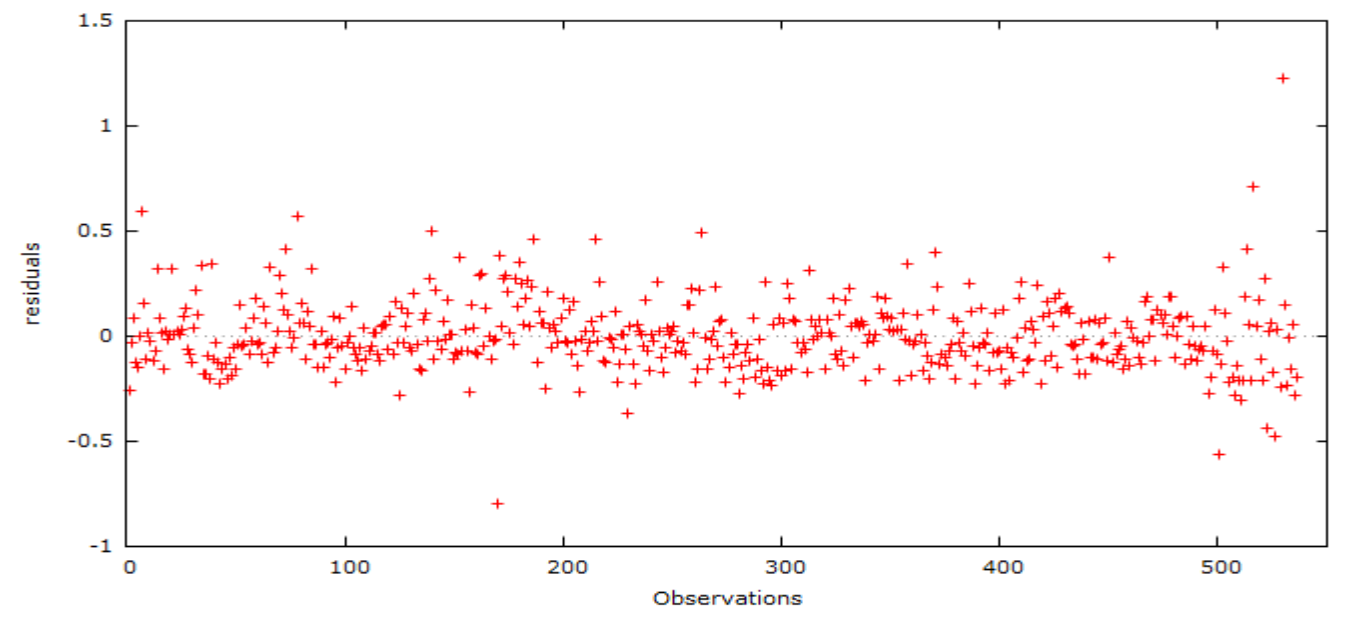

Fig. 1. OLS residuals with 1_PRICE for sample one. Source: own study. 


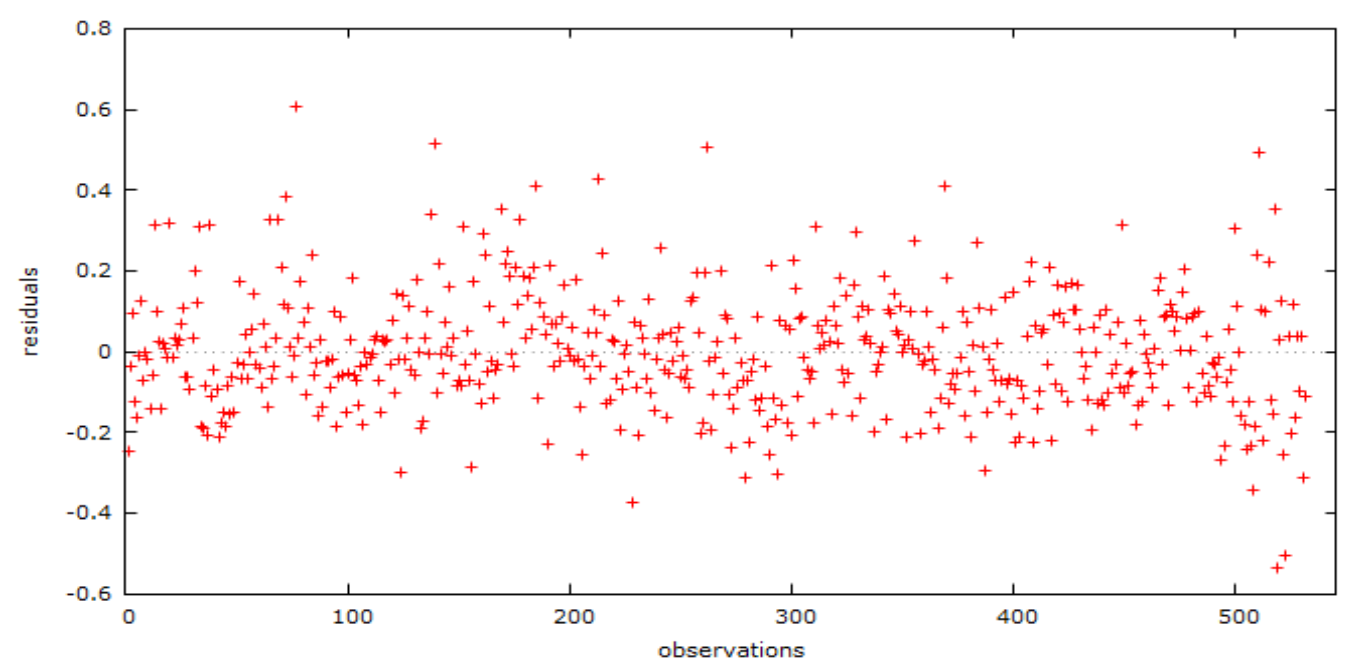

Fig. 2. OLS residuals with 1_PRICE for sample two. Source: own study.

Table 5

OLS model results for sample one and sample two

\begin{tabular}{|c|c|c|c|c|c|}
\hline \multirow{2}{*}{$\begin{array}{l}\text { Variable }(\mathrm{l}=\text { logarithmic } \\
\text { transformation) }\end{array}$} & \multicolumn{5}{|c|}{ OLS for sample one: Model A } \\
\hline & Coefficient & Standard Error & t-Ratio & p-Value & \\
\hline 1_LOTSIZE & 0.072 & 0.017 & 4.172 & $<0.0001$ & *** \\
\hline 1_INCOME & 0.560 & 0.022 & 25.030 & $<0.0001$ & *** \\
\hline 1_FLOORS & -0.008 & 0.025 & -0.298 & 0.766 & \\
\hline 1_SECURITY & 0.063 & 0.030 & 2.075 & 0.038 & ** \\
\hline 1_SERVICES & 0.006 & 0.023 & 0.249 & 0.803 & \\
\hline 1_SOCIAL & -0.005 & 0.022 & -0.238 & 0.812 & \\
\hline 1_BATHS & 0.037 & 0.033 & 1.101 & 0.271 & \\
\hline 1_ROOMS & -0.016 & 0.035 & -0.459 & 0.646 & \\
\hline 1_SPORTS & 0.019 & 0.021 & 0.916 & 0.360 & \\
\hline BUILDING & 0.002 & 0.000 & 20.320 & $<0.0001$ & $* * *$ \\
\hline PARKING & 0.009 & 0.009 & 0.992 & 0.322 & \\
\hline SPOOL & 0.024 & 0.018 & 1.346 & 0.179 & \\
\hline GYM & 0.057 & 0.023 & 2.538 & 0.012 & ** \\
\hline WTRAILS & 0.043 & 0.023 & 1.865 & 0.063 & * \\
\hline BBQ & -0.020 & 0.020 & -1.011 & 0.312 & \\
\hline VERTICAL & 0.068 & 0.025 & 2.778 & 0.006 & *** \\
\hline VIEWS & 0.034 & 0.008 & 4.402 & $<0.0001$ & *** \\
\hline const & 10.594 & 0.081 & 131.300 & $<0.0001$ & $* * *$ \\
\hline $\mathrm{F}$ & 277.909 & & & $1.00 \mathrm{E}-28$ & $* * *$ \\
\hline White's test (squares only) & 122.026 & & & 2.23E-13 & $* * *$ \\
\hline Breusch-Pagan test & 354.625 & & & $5.38 \mathrm{E}-65$ & *** \\
\hline Normality Test (Chi-square) & 171.628 & & & 5.39E-38 & $* * *$ \\
\hline Log-likelihood & 196.444 & & & & \\
\hline Akaike criterion & -356.888 & & & & \\
\hline Schwarz criterion & -279.740 & & & & \\
\hline Hannan-Quinn & -326.708 & & & & \\
\hline R-squared & 0.901 & & & & \\
\hline Adjusted R-squared & 0.898 & & & & \\
\hline $\mathrm{n}$ & 537 & & & & \\
\hline
\end{tabular}


Table 5 con.

\begin{tabular}{|c|c|c|c|c|c|}
\hline \multirow{2}{*}{$\begin{array}{l}\text { Variable }(\mathrm{l}=\log \text { arithmic } \\
\text { transformation })\end{array}$} & \multicolumn{5}{|c|}{ OLS for sample two: Model B } \\
\hline & Coefficient & Standard Error & t-Ratio & p-Value & \\
\hline 1_LOTSIZE & 0.061 & 0.011 & 5.544 & $<0.0001$ & *** \\
\hline 1_INCOME & 0.554 & 0.012 & 44.510 & $<0.0001$ & $* * *$ \\
\hline 1_FLOORS & -0.037 & 0.013 & -2.756 & 0.006 & *** \\
\hline 1_SECURITY & 0.043 & 0.016 & 2.612 & 0.009 & $* * *$ \\
\hline 1_SERVICES & & & & & \\
\hline 1_SOCIAL & & & & & \\
\hline 1_BATHS & & & & & \\
\hline 1_ROOMS & & & & & \\
\hline 1_SPORTS & 0.022 & 0.011 & 1.981 & 0.048 & $* *$ \\
\hline BUILDING & 0.003 & 0.000 & 36.800 & $<0.0001$ & $* * *$ \\
\hline PARKING & & & & & \\
\hline SPOOL & 0.028 & 0.009 & 3.254 & 0.001 & $* * *$ \\
\hline GYM & 0.046 & 0.011 & 4.140 & $<0.0001$ & $* * *$ \\
\hline WTRAILS & & & & & \\
\hline BBQ & & & & & \\
\hline VERTICAL & 0.062 & 0.013 & 4.760 & $<0.0001$ & *** \\
\hline VIEWS & 0.028 & 0.005 & 5.601 & $<0.0001$ & *** \\
\hline const & 10.672 & 0.052 & 207.100 & $<0.0001$ & $* * *$ \\
\hline $\mathrm{F}$ & 1053.282 & & & 0.000 & $* * *$ \\
\hline White's test (squares only) & 26.002 & & & 0.074 & . \\
\hline Breusch-Pagan test & 4.796 & & & 0.904 & \\
\hline Normality Test (Chi-square) & 12.278 & & & 0.002 & $* * *$ \\
\hline Log-likelihood & 356.650 & & & & \\
\hline Akaike criterion & -858.520 & & & & \\
\hline Schwarz criterion & -815.207 & & & & \\
\hline Hannan-Quinn & -841.332 & & & & \\
\hline R-squared & 0.966 & & & & \\
\hline Adjusted R-squared & 0.965 & & & & \\
\hline $\mathrm{n}$ & 379 & & & & \\
\hline
\end{tabular}

Source: own study.

In the second phase, two alternative WLS models were run for sample two in order to correct heteroskedasticity. The results (Table 6) show the correction of heteroskedasticity, measured through the Breusch-Pagan test, since the null hypothesis of homocedasticity was not rejected. The regression coefficients had a better fit with respect to the other models.

In model $\mathrm{C}$, the independent variable SPORTS was not statistically significant and, due to its correlation with the GYM variable, it was excluded from alternative model two. In both cases, the FLOORS regression coefficient was negative, so that in the same building the price of the condominium is lower when the floor level is lower.

After fitting model D to sample two (Table 6), all the independent variables were explanatory for the condos total price. Given the results of the statistical metrics, with a coefficient of determination $\left(R^{2}\right)$ of 0.999 , approximately $99 \%$ of the total variations in the sale price of a home located in a condominium in Costa Rica are explained by the independent variables of the alternative WLS model two.

The regression residuals of the alternative WLS model two have a uniform distribution and a homogeneous dispersion (Fig. 3), typical of the behavior of a normal distribution, statistically significant at $10 \%$. When comparing the original data with the behavior of the projection estimated by the alternative WLS model two (Fig. 4), it is observed that both are almost identical and the prediction of the price of the condominiums is satisfactory. 


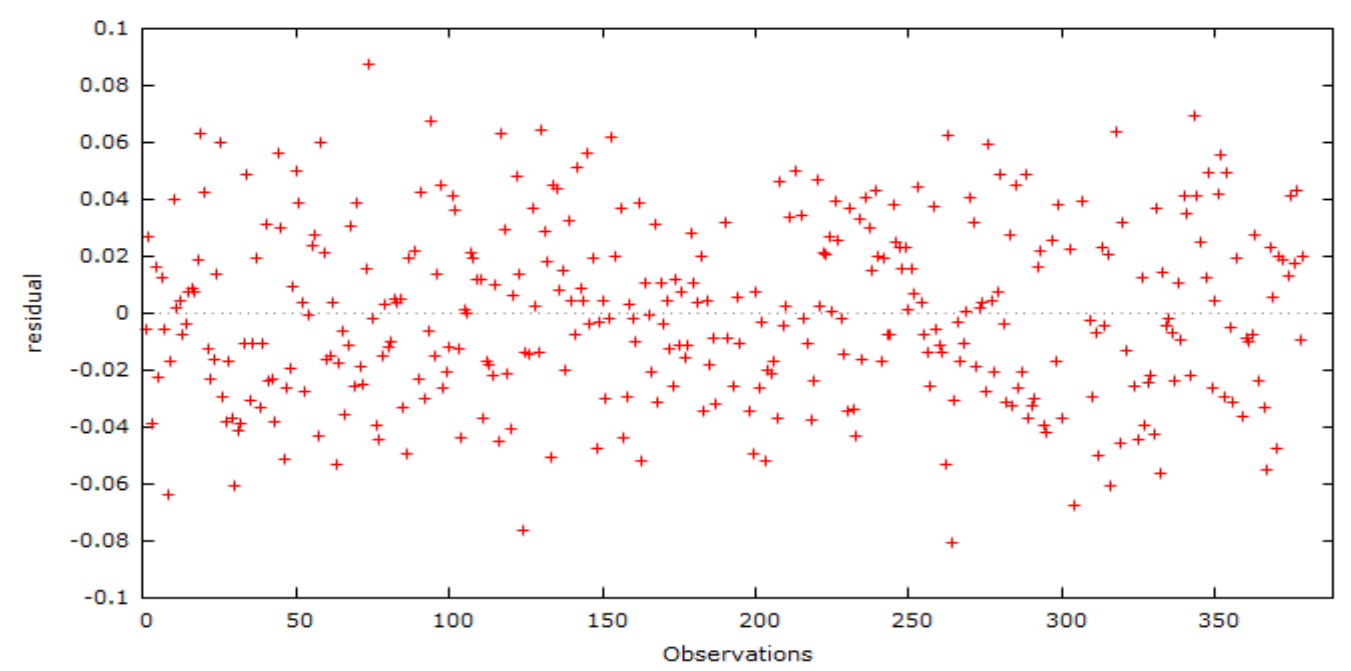

Fig. 3. WLS residuals with 1_PRICE for sample two-alternative two. Source: own study.

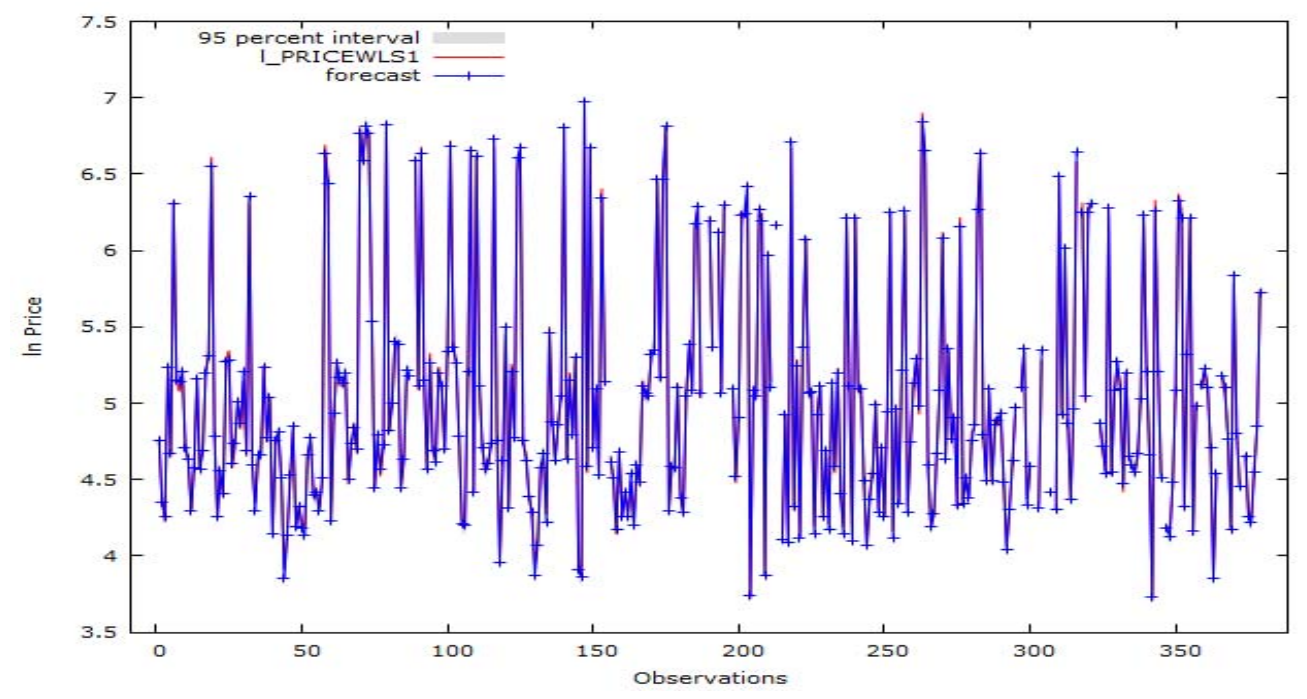

Fig. 4. WLS model fitted data for sample two-alternative two. Source: own study.

Table 6

WLS results for sample two, alternative one and alternative two

\begin{tabular}{|c|c|c|c|c|c|}
\hline \multirow{2}{*}{$\begin{array}{l}\text { Variable }(1=\text { logarithmic } \\
\text { transformation })\end{array}$} & \multicolumn{5}{|c|}{ WLS for sample two: Model C } \\
\hline & Coefficient & Standard Error & t-Ratio & p-Value & \\
\hline 1_LOTSIZE & 0.056 & 0.012 & 4.746 & $<0.0001$ & $* * *$ \\
\hline 1_INCOME & 0.582 & 0.016 & 36.340 & $<0.0001$ & $* * *$ \\
\hline 1_FLOORS & -0.031 & 0.013 & -2.398 & 0.017 & ** \\
\hline 1_SECURITY & 0.040 & 0.017 & 2.390 & 0.017 & ** \\
\hline 1_SPORTS & 0.012 & 0.011 & 1.065 & 0.288 & \\
\hline BUILDING & 0.002 & 0.000 & 28.930 & $<0.0001$ & $* * *$ \\
\hline SPOOL & 0.022 & 0.009 & 2.514 & 0.012 & ** \\
\hline GYM & 0.055 & 0.011 & 4.973 & $<0.0001$ & $* * *$ \\
\hline VERTICAL & 0.062 & 0.012 & 5.108 & $<0.0001$ & $* * *$ \\
\hline VIEWS & 0.026 & 0.005 & 5.202 & $<0.0001$ & $* * *$ \\
\hline const & 10.684 & 0.056 & 191.400 & $<0.0001$ & *** \\
\hline $\mathrm{F}$ & 865901.500 & & & 0.000 & $* * *$ \\
\hline White's test (squares only) & 43.024 & & & 0.005 & *** \\
\hline Breusch-Pagan test & 15.903 & & & 0.145 & \\
\hline
\end{tabular}




\begin{tabular}{l|rrr}
\hline Normality Test (Chi-square) & 6.102 & 0.047 & $* *$ \\
Log-likelihood & 738.570 & & \\
Akaike criterion & -1455.139 & \\
Schwarz criterion & -1412.484 & \\
Hannan-Quinn & -1438.173 & \\
R-squared & 1.000 & \\
Adjusted R-squared & 0.998 & \\
$\mathrm{n}$ & 357 & \\
\hline
\end{tabular}

Table 6 con.

\begin{tabular}{|c|c|c|c|c|c|}
\hline \multirow{2}{*}{$\begin{array}{l}\text { Variable }(1=\operatorname{logarithmic} \\
\text { transformation) }\end{array}$} & \multicolumn{5}{|c|}{ WLS for sample two: Model D } \\
\hline & Coefficient & Standard Error & t-Ratio & p-Valu & \\
\hline 1_LOTSIZE & 0.057 & 0.012 & 4.783 & $<0.0001$ & $* * *$ \\
\hline 1_INCOME & 0.582 & 0.016 & 36.330 & $<0.0001$ & *** \\
\hline 1_FLOORS & -0.030 & 0.013 & -2.347 & 0.020 & ** \\
\hline 1_SECURITY & 0.042 & 0.016 & 2.542 & 0.012 & ** \\
\hline 1_SPORTS & & & & & \\
\hline BUILDING & 0.002 & 0.000 & 28.910 & $<0.0001$ & *** \\
\hline SPOOL & 0.023 & 0.009 & 2.634 & 0.009 & $* * *$ \\
\hline GYM & 0.058 & 0.011 & 5.546 & $<0.0001$ & $* * *$ \\
\hline VERTICAL & 0.062 & 0.012 & 5.101 & $<0.0001$ & $* * *$ \\
\hline VIEWS & 0.027 & 0.005 & 5.268 & $<0.0001$ & $* * *$ \\
\hline const & 10.682 & 0.056 & 191.400 & $<0.0001$ & $* * *$ \\
\hline $\mathrm{F}$ & 952125.200 & & & $0.0 \mathrm{e}+00$ & $* * *$ \\
\hline White's test (squares only) & 40.761 & & & 0.004 & $* * *$ \\
\hline Breusch-Pagan test & 15.530 & & & 0.114 & \\
\hline Normality Test (Chi-square) & 5.767 & & & 0.056 & * \\
\hline Log-likelihood & 737.986 & & & & \\
\hline Akaike criterion & -1455.971 & & & & \\
\hline Schwarz criterion & -1417.194 & & & & \\
\hline Hannan-Quinn & -1440.548 & & & & \\
\hline R-squared & 0.999 & & & & \\
\hline Adjusted R-squared & 0.998 & & & & \\
\hline $\mathrm{n}$ & 357 & & & & \\
\hline
\end{tabular}

Source: own study.

\section{Discussion and conclusions}

The regression coefficient of BBQ and SOCIAL is negative, contrary to expectations. This could be due to the loss of privacy due to the proximity between the house and the social areas. This result was also documented by Chan et al. (1998).

Once the explanatory variables were corrected with statistical inconsistencies, similar behavior patterns to the results of Monson (2009), who demonstrated the statistical importance of variables such as access to the garage, swimming pool, outdoor space, security systems and storage warehouses, were obtained.

Although this study included all areas of the country, the expected significance was obtained in the VIEWS variable, just like in Yu et al. (2005), who demonstrated a greater willingness to pay for ocean view condos. In addition, amenities such as pools and gyms were attractive to the Costa Rican market. In contrast, the model by Chan et al. (1998) presented a negative sign for services related to the pool, spa and recreation, which could indicate low acceptance in consumer tastes and preferences.

This research demonstrated a significant effect of lot size on the price of condominiums. In Canada, it was shown that the lot size, the number of bedrooms, bathrooms, parking spaces and garages, positively explained the prices of residential homes (Ogwang \& Wang, 2003). 


\section{$\$$ sciendo}

The construction area was an influencing factor in the price of real estate, similar to Wen et al. (2005), with the difference of applying logarithmic transformation to the data. In addition, this paper shows a greater preference for vertical condos in the Costa Rican real estate market, since the regression coefficient VERTICAL indicates that the price of the property increases if it is located in a vertical building. This could be due to higher demand for such buildings on the market.

Income limits the possibility to purchase and was the variable with the greatest effect on the prices of condos. The relationship between the price of housing and the income of the population has affected the access of young people and the middle class to purchase as unaffordable prices prevail in Taiwan (Chin-Oh \& Shu-Mei, 2018).

The total area, lot size and the type of condominium (vertical or horizontal) are indispensable attributes when acquiring a property. In addition, access to swimming pools, a gym and a panoramic views are also valued, as well as basic security features. This study did not consider external variables, such as proximity to the city center, population density or access to public transport, which were found useful by Czinkan \& Horváth (2019). Variables such as surrounding green areas or excessive contamination were also not considered, so it is recommended to include them in future research.

Today, the attributes are presented in the real estate market regardless of the social class since along with higher incomes, the population prefers better housing solutions, with more comforts and satisfaction than the previous income percentile. This research will allow real estate developers in Costa Rica to evaluate the characteristics that condominiums must offer, and will make it easier for appraisers, investors and financial entities to value assets with multiple attributes.

\section{References}

Bastian, C., McLeod, D., Germino, M., Reiners, W., \& Blasko, B. (2002). Environmental amenities and agricultural land values: A hedonic model using geographic information systems data. Ecological Economics, 40(3), 337-349. https:// doi.org/10.1016/S0921-8009(01)00278-6

Chan, S. H., Chu, S.-H., Lentz, G., \& Wang, K. (1998). Intra-project externality and layout variables in residential condominium appraisals. Journal of Real Estate Research, 15(1/2), 131-145.

Chin, T., \& Chau, K. (2003). A critical review of literature on the hedonic price model. International Journal for Housing Science and Its Applications, 27(2), 145-165.

Chin-Oh, C., \& Shu-Mei, C. (2018). Dilemma of housing demand in Taiwan. International Real Estate Review, 21(3), 397-418.

Colwell, P., \& Dilmore, G. (1999). Who was first? An examination of an early hedonic study. Land Economics, 75(4), 620-626. https:// doi.org/10.2307/3147070

Court, A. (1939). Hedonic price indexes with automotive examples. In The dynamic of automobile demand, 77-99. General Motors Corporation.

Cowling, K., \& Cubbin, J. (1972). Hedonic price indexes for United Kingdom cars. Economic Journal (London), 82(327), 963-978. https:// doi.org/10.2307/2230261

Cubero, A. (2018). Vertical works and small spaces will be a real estate trend. La República. https://www.larepublica.net/noticia/obras-verticales-y-espacios-pequenos-seran-tendenciainmobiliaria

Czinkan, N., \& Horváth, Á. (2019). Determinants of housing prices from an urban economic point of view: Evidence from Hungary. Journal of European Real Estate Research, 12(1), 2-31. https://doi.org/10.1108/JERER-10-2017-0041

Das, P., Smith, P., \& Gallimore, P. (2018). Pricing extreme attributes in commercial real estate: The case of hotel transactions. The Journal of Real Estate Finance and Economics, 57, 264-296. https://doi.org/10.1007/s11146-017-9621-4

Frew, J., \& Jud, D. (2003). Estimating the value of apartment buildings. Journal of Real Estate Research, 25(1), 77-86. https:// doi.org/10.1080/10835547.2003.12091101

Garza, J. (2019). Vertical condominium is an option for millennials. La República. https://www.larepublica.net/noticia/condominio-vertical-es-una-opcion-para-millennials

Gujarati, D., \& Porter, D. (2010). Econometrics (5th ed.). McGraw-Hill/Interamericana.

Haas, G. (1922). Sale prices as a basis for farm land appraisal (Technical Bulletin No. 9). The University of Minnesota. http://hdl.handle.net/11299/203942

INEC. (2020). Housing: Characteristics of housing and access to services according to planning zone and region. Instituto Nacional de Estadística y Censos. https://www.inec.cr/vivienda 
Lancaster, K. (1966). A new approach to consumer theory. Journal of Political Economy, 74(2), 132-157. https://doi.org/10.1086/259131

Madrigal, M. L. (2020). Slowly, Costa Rica is moving further away from the ground. El Financiero. https:// www.elfinancierocr.com/economia-y-politica/lentamente-costa-rica-se-pasa-a-vivir-maslejos/CYI3VKQPFNDG7CGIB5SQC5URPQ/story/

Mayer, M., Bourassa, S., Hoesli, M., \& Scognamiglio, D. (2019). Estimation and uptading methods for hedonic valuation. Journal of European Real Estate Research, 12(1), 134-150. https://doi.org/10.1108/JERER-08-2018-0035

Miller, N., \& Sklarz, M. (1987). Multiple regression condominium valuation with a touch of behavioral theory. The Appraisal Journal, 55(1), 108-115.

Mok, H., Chan, P., \& Cho, Y. (1995). A hedonic price model for private properties in Hong Kong. The Journal of Real Estate Finance and Economics, 10(1), 37-48. https:// doi.org/10.1007/BF01099610

Monson, M. (2009). Valuating using hedonic pricing models. Cornell Real Estate Review, 7, 62-73.

Ogwang, T., \& Wang, B. (2003). A hedonic price function for a northern BC community. Social Indicators Research, 61(3), 285-296. https://doi.org/10.1023/A:1021905518866

Palmquist, R. (1984). Estimating the demand for the characteristics of housing. The Review of Economics and Statistics, 66(3), 394-404. https://doi.org/10.2307/1924995

Ridker, R., \& Henning, J. (1967). The determinants of residential property values with special reference to air pollution. The Review of Economics and Statistics, 49(2), 246-257. https:// doi.org/10.2307/1928231

Rosen, S. (1974). Hedonic prices and implicit markets: Product differentiation in pure competition. Journal of Political Economy, 82(1), 34-55. https://doi.org/10.1086/260169

Solano, F., \& Aguilar, J. (2019). Housing and urban development situation in Costa Rica, 2018. FUPROVI. [Informe nacional], https://www.fuprovi.org/

Tajima, K. (2019). Shared amenities' impacts on condominium resale values. International Journal of Housing Markets and Analysis, 13(2), 281-297. https://doi.org/10.1108/IJHMA-03-2019-0038

Tetteh, K. (2019). Determining house prices in data-poor countries: Evidence from Ghana. International Real Estate Review, 22(4), 571-595.

Tse, R. (2002). Estimating neighbourhood effects in house prices: Towars a new hedonic model $\begin{array}{llll}\text { approach. Urban Studies (Edinburgh, Scotland), 39(7), 1165-1180. } & \end{array}$ https://doi.org/10.1080/00420980220135545

Wen, H., Jia, S., \& Guo, X. (2005). Hedonic price analysis of urban housing: An empirical research on Hangzhou, China. Journal of Zhejiang University. Science A, 6(8), 907-914. https://doi.org/10.1631/jzus.2005.A0907

Yu, S. M., Han, S. S., \& CHAI, C. H. (2005). Modeling the value of view in Real Estate Valuation: A 3-D GIS approach. Department of Real Estate, National University of Singapore, 22. 


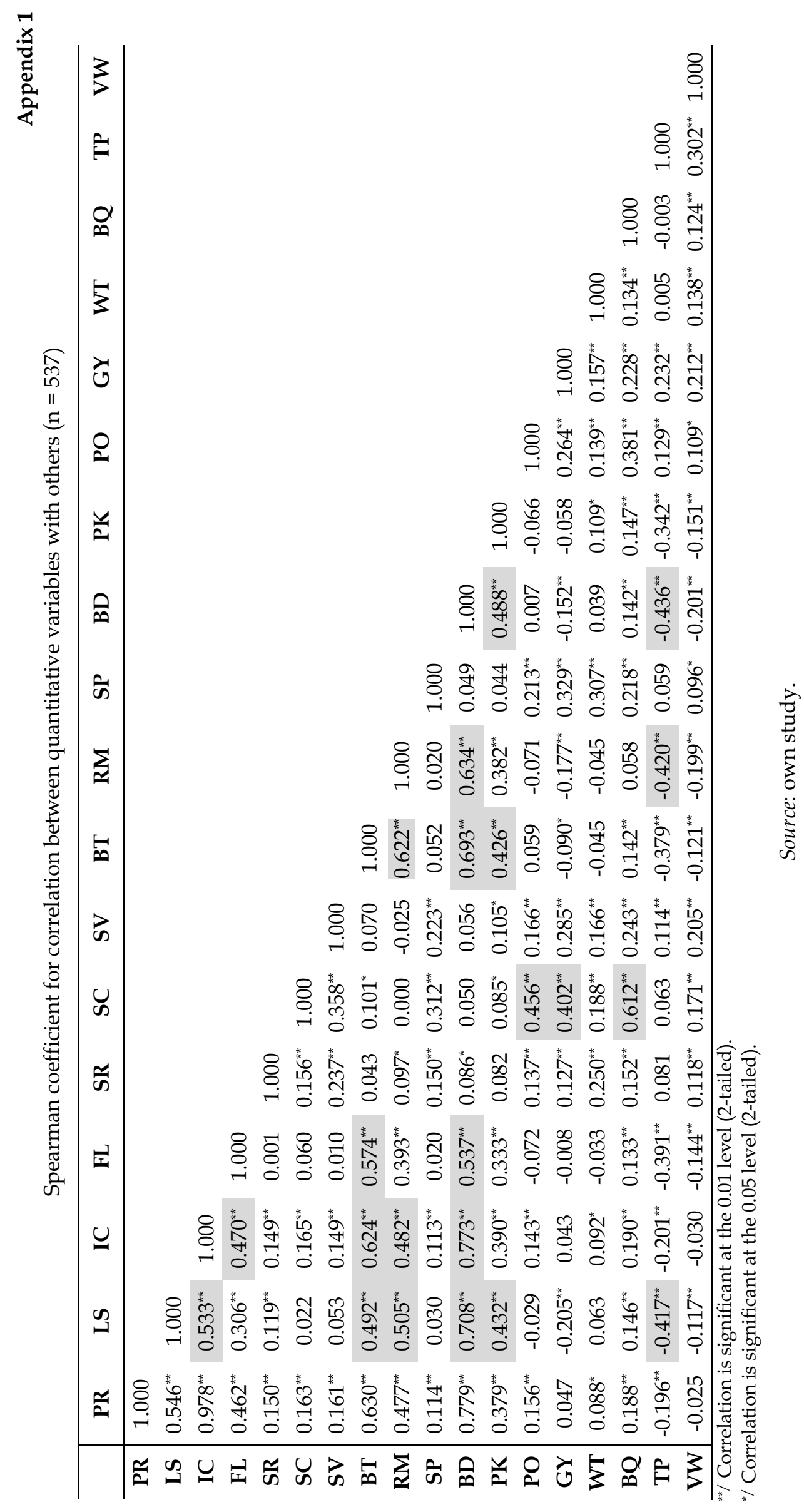

